\title{
UN MEMORIAL POCO CONOCIDO DE LA FÁBRICA DEL ALCÁZAR DE TOLEDO DE $1548^{*}$
}

La importancia que para el arte español reviste el Alcázar de Toledo justifica el que no deba desdeñarse cualquier dato que contribuya al esclarecimiento de su proceso constructivo ${ }^{1}$. A pesar del tiempo transcurrido, las palabras con las que Martín González iniciaba su conocido estudio sobre el Alcázar de Toledo siguen vigentes en la actualidad. Es cierto que publicaciones posteriores, con aportación de nuevos documentos e interpretaciones, han contribuido a resolver gran parte de las numerosas incógnitas surgidas en torno a la construcción en el siglo XVI de un edificio carente de documentación gráfica contemporánea, y sometido, a partir del siglo XVIII a múltiples destrucciones y reconstrucciones ${ }^{2}$.

Sin embargo, la ausencia hasta ahora de un estudio global que comprenda, tanto el análisis material de esta obra arquitectónica, como los aspectos administrativos, sociales y económicos de su fábrica, posibilita al historiador el hallazgo de cuando en cuando de documentación inédita que permite una mejor comprensión, al menos parcial, del desarrollo constructivo de la obra.

Al respecto, el informe que centra este trabajo: Memorial de lo que se ha hecho en las obras de los alcázares de Toledo después de que el Príncipe Nuestro Señor las vio, fechado con toda probabilidad a principios de 1548 y firmado por el veedor de la obra, Juan Bautista Oliverio, y el pagador Alonso de Mazuelas ${ }^{3}$, viene a completar un panorama edificatorio discontinuo en sus datos, si bien globalmente entendible merced tanto a informes y memoriales posteriores, ya conocidos, de los años 1550,1552 y $1557^{4}$, -con noticias precisas acerca del estado en que por entonces se hallaban las obras del Alcázar-, como a los documentos de pago de destajos de cantería, albañilería y carpintería efectuados en su fábrica desde 1542 en adelante ${ }^{5}$, sin olvidar el aporte de datos relativos a los contratos de obra y sus correspondientes condiciones suscritos por maestros y oficiales de diferentes especialidades ${ }^{6}$.

Precisamente, el cotejo de estos y otros documentos ya publicados procura una mejor interpretación del contenido del Memorial: un resumen de lo edificado desde la visita realizada a las obras del Alcázar por el Príncipe -quizá efectuada con anterioridad de finales de mayo de 1547, antes de su partida a las Cortes de Monzón donde estuvo hasta el 9 de diciembre del mismo año, o bien, con posterioridad a la clausura de dichas Cortes, durante la estancia de Felipe en Alcalá de Henares donde pasó la Navidad de 1547 junto a las Infantas sus hermanas- ${ }^{7}$, de la que hasta ahora no se tenía particular noticia, pero que queda confirmada por el propio encabezamiento del Memorial. Por otra parte, este documento informa acerca de lo que se proyectaba construir en el futuro.

* Este estudio tiene su origen en la investigación llevada a cabo en el marco del Proyecto: "La Corte de los Reyes de Bohemia (Maximiliano y María de Austria) en Valladolid (1548-1551): Su influencia en las Artes". Programa General de Apoyo a la Investigación (JCYL). Ref. VA070/03.

${ }^{1}$ Martín GonzÁlez, JuAn José, "Nuevos datos sobre la construcción del Alcázar de Toledo", Revista de Archivos, Bibliotecas y Museos, tomo LXVIII (1960), pp. 271-286.

${ }^{2}$ Marías, Fernando, La arquitectura del Renacimiento en Toledo (1541-1631), vol. IV, Madrid, 1986, p. 51. Véase también Fernando Marías "El Alcázar de Toledo. El Palacio renacentista", en El Alcázar de Toledo. Palacio y Biblioteca: Un proyecto cultural para el siglo XXI, Toledo, 1998, pp. 33-42, y ZolLE BETEGÓN, LuIs, Los alcázares reales en la época de los Austrias, Madrid, 2003.

3 Archivo General de Simancas (AGS), sección Cámara de Castilla (C.C.), legajo 296, folio 87.

${ }^{4}$ AGS, sec. Casas y Sitios Reales, leg. 271, fol. 4 (1550) y leg. 271, fol. 26 (1552); ambos citados por MarTín GonzÁlez, art. cit., pp. 271 y 272, notas 2 y 3, y por CheCa Cremades, Fernando, Felipe II, mecenas de las artes, Madrid, 1992, pp. 41 y 43. El Memorial de 1557 en Checa, ob. cit., pp. 44-46 y nota 103 del capítulo I.

5 AGS, sec. Contaduría Mayor de Cuentas (C.M.C.) 1. ápoca, leg. 1147.

${ }^{6}$ MARÍAS, ob. cit., pp. 51-76.

7 Kamen, Henry, Felipe de España, Madrid, 1997, pp. 28-31. 
La década de los cuarenta del siglo XVI es significativa tanto para la fábrica del Alcázar de Toledo, como para el resto de las Obras Reales. En lo concerniente a estas últimas, hallamos cambios sustanciales en su contexto organizativo tras las visitas realizadas por don Francisco de Luzón, Gobernador de la Provincia de Castilla, a Aranjuez (5 de agosto de 1548), Alcázar de Madrid y Casa Real de El Pardo (27 del mismo mes y año), frente a la antigua estructura administrativa -uniforme y centralizadora- decidida por Carlos V en $1537^{8}$.

Pero también desde 1545 se venía asistiendo al surgimiento de una nueva política artística que, en el ámbito de las construcciones de la Corona, aparece marcada por el interés personal del Príncipe. Si, hasta entonces, el protagonismo de algunos miembros del Consejo de la Cámara de Castilla -organismo encargado hasta la década de los setenta del siglo XVI de los negocios tocantes a las Obras Reales- había eclipsado cualquier tipo de iniciativa personal del futuro monarca por lo que respecta a su gestión y edificación, la muerte en 1545 del Cardenal Tavera y, dos años más tarde, la del Comendador Mayor Francisco de los Cobos -ambos miembros de la Cámara nombrados en 1543 por Carlos V- permitirán al Príncipe llevar a cabo sus propios deseos en materia constructiva9.

En este sentido, no resulta extraña la aparición en los márgenes del Memorial de 1548 de una serie de comentarios realizados por el propio Felipe. Breves acotaciones que, más tarde, se repetirán una y otra vez en muchos documentos relativos a las empresas arquitectónicas de la Corona. También conviene tener en cuenta que el Memorial surge a raíz de una visita del propio Príncipe, y no por vía de una inspección encomendada a otras personas, como en el caso comentado del Gobernador Luzón.

Señala Marías que hasta 1545 la ausencia de noticias relativas a la realización de trabajos en la fábrica de Toledo hace pensar en una escasa actividad edificatoria, centrada fundamentalmente en obras de desmantelamiento de partes preexistentes del antiguo edificio medieval y cimentación de las nuevas zonas a levantar ${ }^{10}$.

En efecto, hasta ese año las datas o pagos registrados en la fábrica del Alcázar quedan limitados a la compra, transporte y hechura de diversas herramientas y materiales (madera, ladrillo, teja, cal, etc.), así como a la realización de ciertas obras de cantería que, aún sin detallar, parecen hacer referencia a estos trabajos de demolición mencionados ${ }^{11}$.

Pero ya desde principios de 1545, con la plausible terminación de los derribos y el inicio de esa nueva política constructiva del Príncipe, surgen los primeros contratos de obra conocidos -vestíbulo que une la portada del Alcázar con el patio (marzo de 1545) ${ }^{12}$ - y los primeros pagos por destajos con-

8 CAno de Gardoqui García, José Luis, "Visitas de Don Francisco de Luzón, Gobernador de la Provincia de Castilla, a las obras reales de Aranjuez, Alcázar de Madrid y Casa Real de El Pardo (1548-1549)" BSAA arte, vol. LXXII-LXXIII (20062007), pp. 51-61. No obstante, algunos puntos de la antigua estructura habían sufrido modificaciones con anterioridad a 1548. Así, el 1 de marzo de 1543, una cédula real expedida por Carlos V decidía la separación definitiva de las competencias ejecutivas conjuntas que, desde 1537, habían venido desempeñando los maestros mayores Alonso de Covarrubias y Luis de Vega en los alcázares de Sevilla, Toledo y Madrid; de forma que Covarrubias quedaba adscrito a las obras de Toledo, mientras que Vega se hacía cargo de las obras de Madrid y de El Pardo, antiguo pabellón de caza demolido ese mismo año cuya reconstrucción será encomendada a Vega. Es significativo que la propia cédula haga mención a la principal razón de este notable cambio organizativo: y ahora habiendo mandado que se labre en los alcázares de Toledo, habemos ordenado que de aqui en adelante uno de ellos (de los dos maestros) resida en las de Toledo, y queremos que sea pagado alli por el nuestro pagador de ellas... que de aquí adelante pague al dicho Alonso de Covarrubias el salario y los días de residencia que hubiere de haber conforme a su asiento; es decir, 25.000 maravedíes anuales y 4 reales al día de los que sirviere (AGS, C.M.C. 1. ép., leg. 1147). En la data del entonces pagador del Alcázar de Toledo, Blas Línez, consta el pago a Covarrubias de 7. 444 maravedíes por cincuenta días que sirvió y residió en las dichas obras desde lunes, 6 de noviembre de 1542 hasta fin de diciembre de él (Ibid.).

9 Díaz González, F. J., La Real Junta de Obras y Bosques en la época de los Austrias, Madrid, 2002, pp. 21 y 70-72.

${ }^{10}$ MARíAs, La Arquitectura del Renacimiento, nota supra, p. 52.

11 En las datas del pagador de la obra del Alcázar de Toledo consta, el 10 de noviembre de 1542, el pago por diversas labores de cantería cuando se comenzó a derrocar el dicho Alcázar (AGS, sec. C.M.C., 1. ép., leg. 1147).

${ }^{12}$ MARÍAS, ob. cit., p. 52. 
cretos: una pared en la calle de Santa Leocadia; linteles para las ocho luces de las cantinas del cuarto de la delantera en el sector norte del edificio (febrero de 1545); rejas para estas luces que iluminan las bóvedas de dicho cuarto, realizadas por Francisco de Villalpando (marzo del mismo año): otras seis rejas debidas a Villalpando, cuatro para las luces de las bóvedas del Cuarto de los Emperadores, en el sector del poniente, y dos para las luces de las bóvedas del cuarto de la escalera principal (noviembre); labra y transporte de sillares de berroqueña de Villaverde y Sonseca para la torre noroeste sobre la Alhóndiga que, por entonces, se estaba levantando de nuevo (septiembre), etc. ${ }^{13}$.

$\mathrm{Al}$ año siguiente, aumenta el número de destajos, ahora referidos a la labra de las ventanas correspondientes a las cuatro torres del Alcázar en su primer nivel; al tallado de tondos, escudos $\mathrm{y}$ otros adornos para dichas ventanas y para las seis del piso inferior de la delantera; antepechos y cornisas para las ventanas de las dependencias de oficios, situadas encima de la Caballeriza principal, en la zona oriental del edificio; talla de vigas de madera para los suelos de las habitaciones situadas debajo del Cuarto de los Emperadores y para los cuartos del lado norte, en la delantera, etc. ${ }^{14}$. Destaca también, en febrero de este año de 1546 , la saca, desbaste y talla de los sillares correspondientes a las primeras hiladas de piedra de la portada principal, destajo a cargo del cantero Miguel de Oteiza quien, junto a Enrique Egas (hijo), había contratado dicha obra ${ }^{15}$.

A pesar del buen ritmo constructivo, los años siguientes observan un significativo incremento de los trabajos, con la contratación de nuevas partes de la fábrica en $1547^{16}$ y el aumento en 1548 de los pagos por nuevos destajos de cantería, albañilería y carpintería ${ }^{17}$. De tal inflexión da fe el Memorial de principios de ese año, el primero referido a las obras del Alcázar del que se tiene noticia. Es probable que la visita del Príncipe Felipe a la fábrica en 1547 sirviera de acicate para la aceleración de los trabajos.

En efecto, lo primero que señala este informe es que se ha subido desde los fundamentos una torre en la esquina de la calle de Santa Leocadia hasta cuarenta pies de alto en que está hecha la primera bóveda o capilla de abajo, y la segunda se cerrará muy presto con sus cuatro ventanas de berroqueña labradas que ya están asentadas en el segundo suelo de la segunda capilla ${ }^{18}$. Es reseñable la obra de esta torre suroeste, que es la mayor de todas las tres torres nuevas que por esta época se rehicieron, por la celeridad de la edificación, dada su envergadura. Sin embargo, dos años después, si bien la torre ya presentaba cubiertas dos bóvedas y se sube la tercera, no se encontraba tan alta como las otras tres: la antigua del atambor en el noroeste, y las nuevas de sobre la Alhóndiga en el noreste y la del sureste cabe la Coracha y hacia el Hospital de San Antón. Estas tres llegaban en ese momento a la altura de la cornisa que remataba el segundo cuerpo de la delantera del Alcázar, asiento de la galería con la que culminaría esta importante parte del edificio y que fue finalmente realizada en $1552^{19}$. Según el Memorial de 1548, la torre de San Antón, que se junta con el aposento de la cuadra grande, es decir, el antiguo Cuarto Real en la zona de levante, había cerrado su bóveda y subido las paredes hasta el alto de las ventanas altas del aposento postrero y de la sala y cuadra de lo alto del cuarto grande ${ }^{20}$. No resulta extraño el buen ritmo constructivo de esta parte del edificio si se tiene en cuenta que fueron los muros de esta zona este, junto a los de la oeste, los conservados del primitivo Alcázar ${ }^{21}$.

Por otra parte, la temprana construcción de las tres nuevas torres indica que desde los inicios de la fábrica se había decidido respetar la planta original del edificio que repite la idea medieval de palacio-fortaleza en torno a un patio cuadrado con una torre en cada esquina.

\footnotetext{
${ }^{13}$ AGS, sec. C.M.C. 1. ép. leg. 1147.

14 Ibid.

15 Ibid.

16 MARÍAS, ob. cit., pp. 54 y 55.

${ }^{17}$ AGS, sec. C.M.C. 1. ${ }^{a}$ ép., leg. 1147.

18 Id., sec. C.C., leg. 296, fol. 87.

19 Id., sec. C. y S.R., leg. 271, fol. 4 y CHECA, ob. cit., p. 43.

${ }^{20}$ AGS, sec. C.C., leg. 296, fol. 87.

21 CHECA, ob. cit. p. 41.
} 
La obra de reconstrucción del Alcázar principiaría, pues, probablemente con el desmantelamiento, cimentación y elevación de las torres de San Antón y de la Alhóndiga (la obra de esta torre se estaba realizando en $1545^{22}$ ), mientras que la antigua del atambor, quizá por hallarse en buen estado, conservaría su aspecto exterior original si bien, al igual que otras zonas del edificio antiguas y nuevas, se llevará a cabo la regularización y modernización decorativa de sus vanos.

En este sentido, las cuatro ventanas ya asentadas en 1548 en el segundo suelo de la segunda bóveda de la torre de Santa Leocadia observan las mismas características que las seis ventanas contratadas el 15 de mayo de 1545 por el cantero Pedro de Garay para el piso inferior del denominado Cuarto de los Emperadores, en la zona occidental del edificio, a continuación, por tanto, de dicha torre; a saber: de piedra berroqueña de las canteras de Menasalbas (Toledo), dinteladas y con un vano de 5 por 9 pies; sobre los dinteles debían colocarse frontispicios de vuelta redonda, como en las ventanas que se hacian en las torres ${ }^{23}$. Es más, Garay se encargó de la realización de estas diez ventanas, tal como indica el pago de 9.000 maravedíes que recibió por cada una de ellas el 31 de diciembre de $1548^{24}$. Por su parte, siguiendo esta idea de regularización y decoración a la romana, el entallador francés Pierre fue pagado el 7 de octubre del mismo año con la cantidad de 7.480 maravedíes por la obra de once remates y guarniciones de piedra berroqueña de Menasalbas, que cada remate llevaba dos garras a los lados y un candelero encima de talla con relieve... y hojas para la orden primera de las ventanas del Cuarto de los Emperadores y para las ventanas de las torres de Santa Leocadia ${ }^{25}$.

La labra y el asiento de las ventanas de la zona oeste del Alcázar en su primer nivel indican que por esta época la obra del muro de este sector había concluido a esta altura. En efecto, el Memorial de 1548 señala que desde la dicha torre (de Santa Leocadia) se ha traído y labrado todo el paño a la larga que hay hasta la torre vieja del atambor, que lleva de grueso diez pies y sube hasta recibir el maderamiento de los entresuelos, con seis ventanas grandes de berroqueña con sus remates y escudos de armas que están asentadas. En este paño o muralla van otras ventanas más bajas con sus rejas de hierro que dan luz a las bóvedas de lo bajo. Al margen de este párrafo, el Príncipe Felipe da su conformidad con la palabra bien ${ }^{26}$.

Estas bóvedas, situadas debajo del Cuarto de los Emperadores, corresponden a cuatro habitaciones grandes destinadas a los servicios; piezas localizadas, por tanto, en el sector occidental del denominado claustro bajo o, lo que es lo mismo, el subsuelo del Alcázar conformado a modo de un complicado entramado de diferentes piezas unidas por corredores, con techos abovedados de ladrillo y sus respectivas puertas de entrada y salida a este patio subterráneo ubicado debajo del patio del Alcázar. Y es que, como señala Checa, la peculiar y escarpada orografía de Toledo impedía de todo punto plantear unas casas de oficios independientemente del núcleo principal del edificio ${ }^{27}$.

Estas cuatro habitaciones, descritas en el Memorial de 1550 como grandes y muy claras y habitables para aposento de gente de servicio, con sus chimeneas y luces altas a la calle, con sus rejas de hierro grueso que vendrán sobre el terraplén que se hiciere ${ }^{28}$, habían visto cerrar sus bóvedas de ladrillo dos años antes, tal como queda señalado en nuestro informe, y ya estaban provistas de sus puertas al claustro bajo que va a la redonda debajo del patio; y estas piezas y bóvedas quedan acabadas y empedradas de ladrillo de canto para los oficios de la casa ${ }^{29}$.

\footnotetext{
${ }^{22}$ AGS, sec. C.M.C. 1. ép. leg. 1147.

${ }^{23}$ MARÍAS, ob. cit., p. 54.

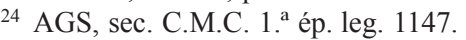

${ }^{25}$ Ibid.

${ }^{26}$ Id., sec. C.C., leg. 296, fol. 87.

27 CHECA, ob. cit., p. 45.

${ }^{28}$ AGS, sec. C. y S.R., leg. 271, fol. 4.

${ }^{29}$ Id., sec. C.C., leg. 296, fol. 87.
} 
También en este claustro subterráneo, pero en la zona oriental del Alcázar, justo encima de la Caballeriza principal -dotada de dos salidas en rampa al norte y al sur de este claustro bajo, continuadas por otras dos rampas en la misma dirección que salen al patio principal-e inmediatamente debajo del Cuarto Real antiguo, se dispusieron siete aposentos o piezas muy claras y alegres, con sus puertas hacia el claustro bajo y ventanas hacia el denominado Corral de Pavones, próximo a la torre sureste o de San Antón ${ }^{30}$.

Los trabajos de blanqueado de estas siete habitaciones, también destinadas a oficios, que, junto a un retrete para guardarropa, venían a ocupar todo el lienzo de levante, habían sido contratados por el albañil Esteban Díaz en noviembre de $1547^{31}$. Meses después, según el Memorial de 1548, el blanqueado había concluido, y están hechas puertas y ventanas para ellos (las siete piezas), y quedarán enladrillados y chapados y acabados del todo para poderse morar de aquí a fin de marzo ${ }^{32}$.

Fue realmente en junio de 1548 cuando quedaron terminadas las obras previstas en estas siete piezas, de cuyo aspecto original proporciona cierta idea el documento de pago del destajo de los soladores Alonso de Sevilla y Diego Hernández, que nos habla de techos abovedados de ladrillo y blanqueados de yeso; suelos de ladrillo pulido con adornos de azulejos a base de cintas y coronas; paredes chapadas de azulejo en su parte inferior; puertas y ventanas también chapadas de azulejos con labores de lazo, etc..$^{33}$.

Estas habitaciones se hallaban comunicadas con el antiguo Cuarto Real mediante una escalera de caracol secreta, embutida en la pared de dicho cuarto, cuyos pasos y mesas también presentaban chapados de azulejería ${ }^{34}$.

Respecto a la Caballeriza principal, situada como se dijo debajo de estas dependencias, nuestro Memorial señala cómo, a principios de 1548, se acaban ahora de cerrar los tres arcos de la escalera del zaguán de las puertas de las caballerizas que sale al corral de pavones y baja desde el claustro ${ }^{35}$.

Pero, quizá son más interesantes los comentarios contenidos en dicho Informe acerca del estadio constructivo en que se hallaba por entonces la delantera del Alcázar y su portada principal en el sector septentrional. Y esto, no solamente porque la entidad de los trabajos allí emprendidos, en la parte más representativa del Alcázar, permitían cerrar el cuadro del edificio -idea de cuadro o cuadrado que es una constante del proceso edificatorio del Alcázar en el respeto a la planta del primitivo palacio fortaleza medieval ${ }^{36}$-, sino también por cuanto la fachada, compuesta de tres cuerpos separados por cornisas, se compone, como señala Checa, a la manera renacentista, como un todo orgánico articulado por los vanos y la portada que

${ }^{30}$ Los antepechos y cornisas de estas ventanas habían sido labrados por el cantero Miguel de Oteiza en agosto de 1546 (Id., sec. C.M.C. 1. 'ép. leg. 1147).

${ }^{31}$ MARÍAS, ob. cit., p. 54.

${ }^{32}$ AGS, sec. C.C., leg. 296, fol. 87.

33 Id., sec. C.M.C., 1. ép. leg. 1147.

34 Ibid.

35 Id., sec. C.C., leg. 296, fol. 87.

${ }^{36}$ En este sentido de respeto sostenido a una traza basada en el cuadrado, el plan arquitectónico seguido en el Alcázar desdeñó la construcción de edificios anejos que pudieran desvirtuar el cuadro fundamental. Al respecto, cuando en 1550 se planteó la necesidad de construir dos nuevas caballerizas debido a la exigüidad de la principal de la zona de levante, prefirióse cavar -empresa dilatada y costosa- el suelo debajo las dependencias proyectadas en el sector de mediodía (cuarto, trascuarto y cocinas) al nivel de la Caballeriza principal, antes que edificarlas fuera del recinto original porque como esta casa no tenga corrales y anchuras sino sólo lo que se encierra en el cuadrado de ella, es menester en esto ensancharla y aprovecharla cuanto sea posible dentro de si misma porque, allende de esto, la hermosea y da autoridad la extrañeza de tantas bóvedas y tan grandes y provechosas, y la costa que se hiciere en picar la dicha piedra y vaciar y ahondar el espacio de las dichas caballerizas, se ahorra doblado en la necesidad que tenemos de la dicha piedra para subir el muro de esta parte de mediodía que está bajo (AGS, sec. C. y S.R., leg. 271, fol. 4). 
centra el conjunto... abandonándose cualquier resabio de la fase decorativa del Renacimiento español ${ }^{37}$.

A principios de 1548, se había acabado de cerrar el cuadro de todo el Alcázar y de igualar otros portillos de la delantera, y asentado el friso y cornisa de berroqueña donde se han de comenzar a hacer las ventanas altas del dicho cuarto delantero, las cuales se están labrando y asentarán en todo el verano que viene hasta recibir las maderas de la galería; y asimismo se labran otras ventanas de las torres del aposento alto ${ }^{38}$. Del destajo del friso, cornisa y arquitrabe de la delantera en su primer cuerpo, entre torre y torre, se había encargado desde febrero de 1546 el cantero toledano Juan López quien, el 7 de junio de 1547 percibió por dicha labor 81.600 maravedíes ${ }^{39}$. Por su parte, la obra de las ventanas del piso noble de la delantera principal había sido contratada por Antón Gómez y el propio López en septiembre de $1547^{40}$.

La obra de la delantera principal, tanto al exterior, como en lo relativo a sus dependencias interiores, como se dirá más adelante, marchaba, pues, a buen ritmo en este año de 1548 . No así la de su portada, trazada por Alonso de Covarrubias y rematada en Enrique Egas (hijo) y en el cantero Miguel de Oteiza, ambos fiados por el escultor Gregorio Pardo ${ }^{41}$, que por esta época habría sufrido un cierto parón, tal como se desprende de nuestro Memorial.

Es cierto que la mayor parte de las piezas requeridas para la construcción de la portada -de granito de Menasalbas- ya se encontraba a principios de 1548 a pie de obra, talladas y desbastadas de acuerdo con las condiciones dadas por Covarrubias dos años antes ${ }^{42}$. La obra de la portada había seguido, por tanto, su curso normal. Sin embargo, tal como informa el Memorial, Juan Bautista Oliverio y Ambrosio de Mazuelas habían entablado pleito por vía de servicio con los fiadores de Maestre Enrique en quién se remató (la portada), que vive en Almagro y no ha querido venir a continuarla; y está dada sentencia contra los dichos fiadores y la cosa en términos que brevemente se dará prisa en ello ${ }^{43}$.

El pleito habría tenido lugar en 1547, pues no consta pago alguno a Egas ni a Oteiza ese año ni el siguiente, lo que hace suponer que, a pesar de la presencia de las piezas de piedra listas para ser levantada la portada, Egas se había desentendido temporalmente de la obra agobiado, sin duda, por la negativa de sus fiadores a entregar una mayor cantidad de dinero de la estipulada en el remate, cuya excesiva baja no habría tenido en cuenta la complejidad de una obra que, una vez emprendida, observó la necesidad de emplear en ella una mayor cantidad de tiempo y de dinero. Al respecto, el 25 de diciembre de 1549, al tiempo de recibir Enrique Egas 225.000 maravedíes a cumplimiento de ochocientos ducados que se le han dado a cuenta de lo que ha de haber por la dicha portada -lo que indica que el Maestre prosiguió el destajo-, fue pagado con 10.000 maravedíes más en que fue tasado y moderado lo que hizo de demasía demás de lo que era obligado conforme a su obligación en las molduras de los tres pilares y en la mejoría de la talla de los colgantes del trofeo sobre del sobrearco, y pedestales y codillos, y en el ripiado de lo que hasta 25 de diciembre del dicho año de 1549 está asentado en la dicha portada ${ }^{44}$.

37 CHECA, ob. cit., p. 43.

38 AGS, sec. C.C., leg. 296, fol. 87.

39 Id., sec. C.M.C. 1. áp. leg. 1147.

40 MARÍAS, ob. cit., p. 54.

41 Id., p. 53.

42 Id. pp. 53 y 54. En febrero de 1546 se registra el primer pago del destajo de la portada principal: 13 hiladas de piedra para el escarzan de la puerta principal, sacadas y desbastadas por Miguel de Oteiza. Por su parte, el 10 de diciembre de 1545, Enrique Egas ya había recibido un primer pago de 75.000 maravedíes para en cuenta de la portada principal que está obligado a hacer en la casa de los dichos alcázares (AGS, sec. C.M.C. 1. ép., leg. 1147).

43 AGS, sec. C.C., leg. 296, fol. 87.

44 Id., sec. C.M.C. 1. ${ }^{a}$ ép., leg. 1147. 
Por esta época se hace patente el urgente deseo de culminar la delantera del Alcázar en el interior y exterior, lo que tendrá lugar finalmente en $1552^{45}$. En tal interés no hay que ver solamente el cumplimiento de un programa edificatorio que desde sus inicios, como se dijo, perseguía la materialización de un trasunto de la antigua fortaleza medieval estructurada a modo de cuadro en su traza general. Existe, quizá también, sobre todo en el ánimo del Príncipe Felipe una clara idea por conformar una cierta imagen de poder vehiculada por la presencia de una cerrada y simplificada arquitectura que, aunque inacabada en esos momentos, sirviera como imagen representativa de una monarquía autoritaria pero, al tiempo, eficiente en sus empresas artísticas.

Esta determinación personal por parte del futuro Monarca se hace explícita en diferentes ocasiones. A principios de 1548, los oficiales del Alcázar manifestaban al Príncipe su malestar por la escasa provisión dineraria encauzada mensualmente hacia las obras y destinada al pago de los destajos, cuyo número había aumentado considerablemente, descuidando la compra de materiales necesarios: para estas obras se dan quinientos ducados cada mes, y demás que estos se pagan mal y se hace costa en cobrarlos de los mayordomos en quien don Juan de Castilla los libra, hay necesidad que este ordinario se acreciente, porque con él luce poco la obra. Asimismo esta obra suele casi cesar los veranos en los meses de junio y julio y agosto por falta de cal y arena, que no viene ni lo hay en estos meses, y para que esto se excuse es menester tenerlo comprado desde el invierno para entonces, y de los dineros ordinarios no se puede proveer. Hay necesidad que para que estas obras anden como conviene y a menos costa, Su Alteza mande proveer de dineros para ello. La respuesta, al margen del párrafo, del Príncipe, es muy clara al respecto: que estos 500 ducados no se gasten en otra cosa sino en la continuación de acabar los dos cuartos delantero (s) y de la mano derecha, como está ordenado ${ }^{46}$.

Dos años más tarde se mantenía la prioridad en la terminación de la delantera, frente a la construcción de ciertas dependencias destinadas a servicios; piezas necesarias, pero indudablemente menos vistosas que los cuartos mencionados; por ejemplo, las dos cocinas grandes y antecocinas de la zona sur del edificio, cuya fábrica se ha dejado para la postre y se labrará el año $1551 . .$. por acabar todo el edificio de los dos cuartos que de nuevo se han hecho, y es el de la delantera y el de la calle de La Magdalena (al poniente) que con el ayuda de Dios quedarán

45 CHECA, ob. cit., p. 43.

46 AGS, sec. C.C., leg. 296, fol. 87. Es difícil establecer parámetros comparativos concretos respecto a los volúmenes de dinero empleados en la edificación de las Obras Reales, tanto por la falta de datos financieros, como por la diferencia de años. No obstante, puede obtenerse una idea aproximativa si, por ejemplo, se tiene en cuenta que la fábrica del Alcázar de Toledo contemplaba una provisión dineraria anual cercana a los 2.500 .000 maravedíes, mientras que la obra del Alcázar de Madrid arrojaba en 1566 la cantidad de 26 millones o 15 millones de maravedíes de promedio anual entre 1581 y 1586. En 1566, la fábrica de El Escorial presentaba 29 millones de maravedíes de provisión dineraria; en 1587 las obras de Aranjuez cerca de 9 millones, y en 1566 las obras del Palacio de Valsaín más de 3 millones (CANO De Gardoqui García, José Luis, “Aspectos económicos relativos a la Fábrica de El Escorial”, en El Monasterio del Escorial y la Arquitectura, Actas del Simposium, San Lorenzo de El Escorial, 2002, pp. 123-174).

La falta de provisión dineraria para las obras del Alcázar de Toledo podía ser paliada mediante diferentes mecanismos. Por ejemplo, desde el punto de vista del acopio de materiales, se aprovechó en diferentes ocasiones el derribo de ciertos sectores del primitivo edificio para la obtención de piedra; así, a principios de 1548, el cuarto y torres del aposento viejo donde ha de ser la escalera principal y el trascuarto de hacia Santa Leocadia (AGS, sec. C.C., leg. 296, fol. 87). Con la misma finalidad, era reutilizada la piedra procedente de las excavaciones realizadas en el edificio tendentes a la construcción de algunas dependencias de servicio, caso de las dos caballerizas del sector de mediodía, situadas debajo de las cocinas (Id., sec. C. y S.R., leg. 271, fol. 4). En lo relativo a la obtención de dinero en efectivo se procedió, como era usual en otras Obras Reales, a la venta de materiales viejos o usados. En el Memorial de 1548, Oliverio y Mazuelas señalaban que hay necesidad de vender alguna madera de la que está en Toledo porque es vieja y se va dañando, y de presente no hay necesidad de toda ella en estas obras. El Príncipe Felipe respondía al margen: que lo vendan hasta en cantidad de 1.000 ducados, y que estos sirvan para los gastos del traer de la dicha madera (comprada el mismo año en la Sierra de Cuenca) y socorrer los destajos (Id., sec., C.C., leg. 296, fol. 87). 
cerradas y tomadas las aguas en este año presente de 550 ... y porque el Príncipe Nuestro Señor mandó que todo el dinero que habíase gastase en estos dos cuartos y no en otra cosa ${ }^{47}$.

Según este Memorial de 1550, la edificación en sus diferentes habitaciones en el nivel inferior del patio principal de los dos cuartos mencionados por el Príncipe -el de la delantera al norte, y el del poniente desde Zocodover a La Magdalena- se hallaba bastante avanzada; particularmente las dos cuadras grandes, una tras otra, situadas a la derecha del zaguán de entrada -próximas a la torre del atambor-, y todo el cuarto del poniente compuesto de tres cuadras o habitaciones con sus correspondientes tránsitos entre ellas ${ }^{48}$. Todas estas piezas ya presentaban su primer suelo asentado de muy gentil maderamiento y muy espeso y vistoso, a base de molduras romanas, aliceres, frisos, canecillos tallados con adornos de medallas, etc.; elementos que vendrían a rimar con las ricas techumbres artesonadas, decoradas también a la romana, cuya contratación se había efectuado entre 1549 y $1559^{49}$. Todo el maderamiento de estos primeros suelos ya estaba labrado a principios de 1548: las vigas y canes y alizeres ... de todo el cuarto de la delantera y del otro cuarto largo de la calle de La Magdalena, lo cual se comenzará a enmaderar la Cuaresma que viene ${ }^{50}$. La labor de labra de la madera para los primeros suelos de la delantera habíase iniciado en febrero de 1546, siendo el maestro de carpintería y vecino de Toledo, Alonso de Córdoba, el encargado de este destajo que comprendía también el correspondiente asiento, lo que tuvo lugar el 19 de septiembre de 1548. En este destajo colaboraron los carpinteros toledanos Yuste de Trujillo y Juan Franco, siendo pagados el 21 de octubre del mismo año con 44.064 maravedíes por 44 vigas asentadas sobre sus soleras y nudillos, con molduras y ventanillas y tabicas a nueve reales cada una, y otros 15.096 maravedies por 222 canes que se añadieron y asentó en el primer suelo con sus cobijas de tablones enteros con una moldura romana atada en cuadrado por todas las piezas alrededor ${ }^{51}$.

Finalmente, debemos reseñar lo que el Memorial de 1548 refiere respecto a otra de las partes importantes del Alcázar: la de su patio cuadrado en torno al cual se articula el edificio, a modo de espacio central y su prolongación en la caja de la escalera principal.

Del sector donde había de ser construida esta escalera ya se ha dicho aquí cómo a principios de 1548 se procedía a derribar el cuarto y torres de antiguas dependencias ${ }^{52}$. Respecto al patio propiamente dicho, hallábanse excavadas por entonces gran parte de las peñas para dos aljibes, los cuales se acabarán este verano; serán tan grandes que cabrán más de cien mil cántaros de agua y más de ciento cincuenta mil ${ }^{53}$.

Quizá resultan más interesantes, por las controversias que planteó su fábrica, las noticias que el Memorial proporciona en lo relativo a la obra de las arquerías alta y baja del patio del Alcázar. No vamos a entrar aquí en los problemas que concurrieron en el proceso contractual de la doble arquería, trazada por Covarrubias y realizada finalmente por Villalpando ${ }^{54}$. Sí decir, no obstante, que a la luz de este Informe y de otros documentos, conviene retrasar la fecha de la primera adjudicación del destajo de esta obra a finales de 1547, pues a principios del año siguiente el pleito con los maestros canteros que habían procedido a su remate-Diego de Cáceres,

47 AGS, sec. C. y S.R., leg. 271, fol. 4.

${ }^{48}$ La primera cuadra de la delantera, situada a la izquierda del zaguán de entrada, ya poseía en 1550 chimenea y huecos para las puertas (Ibid.).

${ }^{49}$ MARÍAS, ob. cit., pp. 55-57.

${ }^{50}$ AGS, sec. C.C., leg. 296, fol. 87.

51 Id., sec. C.M.C. 1. áp. leg. 1147

52 Cfr. nota 45.

53 AGS, sec. C.C., leg. 296, fol. 87. Este aljibe de agua de río se hallaba debajo de una habitación grande que, a su vez, se localizaba debajo del cuarto que está en el patio de la delantera... y tiene agua con boca que sale a esta cuadra para que la gente del claustro (subterráneo) se pueda servir (Id., C. y S.R., leg. 271, fol. 4).

54 Cano de Gardoqui García, José Luis, "Noticias sobre el proceso contractual del patio del Alcázar de Toledo", Boletín del Seminario de Estudios de Arte y Arqueología, vol. LXIII (1997), pp. 359-369. 
Andrés de Vargas, Gaspar Cordero y Manuel Álvarez- ya estaba en marcha debido a que nunca han querido dar fianzas bastantes del cumplimiento de la obra conforme a las condiciones del remate, y por esto no se les osa dar dineros, ni está comenzada la obra. Dase mucha prisa en estos pleitos y en toda la obra, y lo mismo se hará de aqui adelante ${ }^{55}$. Sin embargo, poco antes, estos destajeros habían recibido ya una primera paga de 400 ducados para la compra de herramientas y el desbaste de las primeras piezas de la arquería (columnas) en la cantera ${ }^{56}$. La segunda paga para el transporte de estas piezas a pie de obra ya no tuvo lugar, pues comenzó a haber entre ellos (los destajeros) alguna discordia sobre quién tiene el dinero y otros desórdenes..., y porque vimos que no se atrevian a carretear las piezas que tienen sacadas, porque este es el principal gasto y dificultad de la obra, detuvímonos en dar los dineros ${ }^{57}$. La excesiva baja en el remate -6.500 ducados- de una obra compleja y la falta de recursos económicos a la hora de avalar las posturas de los maestros obligaron, como sabemos, a una nueva contrata y condiciones de las arquerías.

Resulta curioso observar, no obstante, cómo a principios de 1548 los oficiales del Alcázar mostraban fundadas esperanzas en la prosecución de esta obra con los mismos destajeros, pensando que todos los problemas se debían a la falta de una mayor cantidad de provisión dineraria: dada sentencia en el pleito... del arquería del patio y comenzándose a labrar en ella, sería muy grande inconveniente no continuarse como conviene hasta acabarlo; y los maestros no querrían otro achaque sino la falta de los dineros. Su Alteza lo provea, porque los dos mil ducados que el año pasado mandó librar no bastan, ni hay en ellos recaudos para esto, asi porque se ha gastado parte de ellos en las obras en cosas que no se han podido excusar, como porque lo que queda aprovechará poco para lo mucho que es menester para la dicha arquería del dicho patio y para la dicha portada y para el traer de la dicha maderada (comprada en la Sierra de Cuenca ese mismo año), que son cosas que cada día han menester muchos dineros.

Al margen de este párrafo, el Príncipe Felipe insta a acabar este pleito, y que para esto se provea de 1.000 ducados y se escriba a don Juan (de Castilla) sobre ello, lo cual ha de ser demás de los que da cada mes ${ }^{58}$.

No debe descartarse en un futuro el hallazgo de nuevos documentos referentes a las obras del Alcázar de Toledo que, al igual que el Memorial de 1548, vengan a sumarse a datos ya conocidos e interpretados en orden a una mejor comprensión de su proceso edificatorio. Al respecto, el documento analizado en este trabajo llena un vacío importante en el desarrollo de la fábrica toledana, al tiempo de afianzar, aún más si cabe, el significativo cambio acontecido por el ejercicio de las responsabilidades de gobierno de la nación, cuyo control por parte del Príncipe Felipe se torna particularmente activo a partir de 1545. Por lo que aquí interesa, el evidente interés del Príncipe por retomar el planeamiento iniciado por su padre, Carlos V, de restaurar, reconstruir y ampliar las antiguas residencias reales, no tendría su comienzo en la transformación en palacio del viejo pabellón de caza de El Pardo (agosto de 1548). Por el contrario, y al menos un año antes de la orden dada al Gobernador Luzón, la renovación de la vieja fortaleza medieval del Alcázar de Toledo concitaría la primera dedicación práctica de Felipe hacia el diseño y la arquitectura.

José Luis CANo De GardoQui García Universidad de Valladolid

\footnotetext{
55 AGS, sec. C.C., leg. 296, fol. 87.

${ }^{56}$ Id., sec. C. y S.R., leg. 271, fol. 1.

57 Ibid.

${ }^{58}$ Id., sec. C.C., leg. 296, fol. 87.
} 